\title{
Elite athletes' achievement goals, burnout levels, psychosomatic stress symptoms, and coping strategies
}

\author{
Martin Daumiller \\ University of Augsburg
}

\author{
Raven Rinas \\ University of Augsburg
}

\author{
Jennifer Breithecker \\ University of Augsburg
}

\begin{abstract}
Elite athletes undergo intensive training and competitive pressure to succeed, making them susceptible to professional strain. However, they differ in their subjective reactions in the form of burnout levels and psychosomatic stress symptoms. Following a motivational perspective, these differences may be explained by the goals that athletes pursue. The current study therefore examined the effects of elite athletes' achievement goals on their burnout levels and psychosomatic stress symptoms, and to what extent they can be explained by athletes' use of adaptive coping strategies. Based on the answers of 125 German elite athletes, path modelling revealed that mastery approach goals were negatively associated with burnout levels and psychosomatic stress symptoms, while mastery avoidance and performance approach goals were positively associated with burnout levels. Coping strategies partially mediated the effects of mastery approach goals on burnout levels and psychosomatic stress symptoms. These findings suggest practical implications for supporting elite athletes through goal setting processes.
\end{abstract}

Keywords: achievement goals; elite athletes; burnout; coping

¿ 2021, Taylor \& Francis. Daumiller, M., Rinas, R., \& Breithecker, J. (2021). Elite athletes' achievement goals, burnout levels, psychosomatic stress symptoms, and coping strategies. International Journal of Sport and Exercise Psychology. Advanced online publication. https://doi.org/10.1080/1612197X.2021.1877326. This paper is not the copy of record and may not exactly replicate the final, authoritative version of the article. The final article will be available, upon publication, via its DOI.

Elite athletes, distinguished from regular athletes by having attained excellence within their professional sport, constitute a critical population that is focused on highly competitive athletic achievements. In the process of achieving these successes, elite athletes undergo intense training and competitive pressure to succeedmaking burnout levels (the extent to which an athlete feels exhausted, uninterested, etc.) and psychosomatic stress symptoms (e.g., sleep loss, headaches) as well as the use of adaptive coping strategies to handle these experiences, a highly important research topic. In particular, for prevention and intervention, it is crucial to understand personal antecedents of burnout and stress, as not all athletes endure these strains to the same extent, and some not at all (Cresswell \& Eklund, 2007; Feigley, 1984).

Athletes' motivation, which lies at the heart of their thoughts, feelings, and behaviors (Ryan \& Deci, 2000),

Correspondence concerning this article should be addressed to Martin Daumiller, Department of Psychology, University of Augsburg, Universitätsstr. 10, 86159 Augsburg, Germany; Martin.Daumiller@phil.uni-augsburg.de.

We have no known conflicts of interest to disclose. can be considered a compelling research avenue for explaining individual differences in experiences and behaviors surrounding burnout levels, psychosomatic stress symptoms, and the use of coping strategies. Following contemporary understandings of motivation, it is not only a question of how strongly an individual is motivated (i.e., the quantity of motivation), but also the configuration of their motivations (i.e., the quality of motivations; Pintrich, 2000). An established motivational framework that has been effectively used to describe these qualitative motivational differences in athletes and how they are associated with experiences and behaviors is Achievement Goal Theory (e.g., Fernández-Rio, Cecchini Estrada, Mendez-Gimenez, Fernández-Garcia, \& Saavedra, 2014; Isoard-Gautheur, Guillet-Descas, \& Duda, 2013; Kavussanu, 2006; Mascret, Elliot, \& Cury, 2015; Van Yperen, Blaga, \& Postmes, 2014). According to the achievement goal approach, the different goals that individuals pursue guide their interpretations, behaviors, and reactions (including patterns of coping and emotion) in achievement situations (Daumiller et al., 2021; Kaplan \& Maehr, 1999; Tuominen-Soini, Salmela-Aro, \& Niemivirta, 2008). Thus, elite athletes should interpret and handle stressors differently depending on the personal goals they pursue, 
as their goals may directly matter for burnout and psychosomatic stress, and indirectly through their use of adaptive coping strategies (see also Ntoumanis, Biddle, \& Haddock).

Despite the established relevance of achievement goals for the athlete context, surprisingly little research exists concerning the associations of achievement goals with burnout levels and psychosomatic stress symptoms, and also beyond this population, particularly little is known about the mechanisms underlying these associations, such as the use of coping strategies. The limited literature indicates that athletes' achievement goals matter for their experiences of strain. However, more research is needed concerning elite athletes specifically, who have been found to differ in their motivations when compared to non-elite athletes (Kavussanu, White, Jowett, \& England, 2011) and may be at risk for a number of negative outcomes (e.g., Brand, Wolff, \& Hoyer, 2012; Rice et al., 2016). Moreover, investigations which incorporate mediators such as the use of coping strategies to better explain these relationships are highly valuable (Ntoumanis et al., 1999). As such, the aim of the present study was to understand the relationship that specific achievement goals have with burnout levels and psychosomatic stress symptoms in elite athletes, and to elucidate the role of coping strategies in these relationships.

\section{Achievement Goal Theory in the Athlete Context}

Achievement goals represent competence-based end states that individuals strive to either approach or avoid in achievement contexts. Four types of goals are contemporarily distinguished (Conroy, Elliot, \& Hofer, 2003; Elliot \& McGregor, 2001; Harwood, Spray, \& Keegan, 2008; Jaitner et al., 2019; Van Yperen, et al., 2014; Wang, Biddle, \& Elliot, 2006): mastery approach, mastery avoidance, performance approach, and performance avoidance goals.

Mastery approach goals focus on improving competencies, skills, and knowledge, while mastery avoidance goals focus on preventing the stagnation or loss of competencies, skills, and knowledge. Within the athlete context, mastery approach goals are particularly adaptive, as illustrated by positive associations with positive affect and self-esteem through perceiving sports competitions as more challenging and less threatening (Adie, Duda \& Ntoumanis, 2008; see also Adie, Duda, \& Ntoumanis, 2010), enjoyment (Morris \& Kavussanu, 2009), self-determined situational motivation and competence (Fernández-Rio et al., 2014), as well as adaptive perfection striving (Stoeber, Stoll, Pescheck, \& Otto, 2008). On the other hand, mastery avoidance goals are not often investigated, with findings on this goal type being unclear and typically documenting no significant associations or unfavorable associations. Moreover, mastery avoidance goals are criticised for their counterintuitive nature and deemed uncommon in the sports domain (see Ciani \& Sheldon, 2010; cf. Baranik, Stanley, Bynum, \& Lance, 2010). This is also addressed by a general debate within the achievement goal literature about the usefulness of mastery avoidance goals (Murayama, Elliot, \& Friedman, 2012). In the current study, we considered mastery avoidance goals to be of value as elite athletes are known to have high standards for themselves and may be concerned with not meeting self-standards (e.g., "I don't want to lose my specialized sport skills"), prompting this goal type to potentially be highly relevant. Furthermore, such motivations may become particularly salient when athletes approach the peak of their competitive careers (when margins for improvement become smaller and there is a greater risk of losing skills or competencies due to injuries or missed trainings; see Larson, McHugh, Young, \& Rodgers, 2019).

Performance goals in the athlete setting are typically defined in line with Elliot and McGregor (2001) as strivings to perform better than others (performance approach) or to avoid doing worse than others (performance avoidance). Regarding performance approach goals, findings in the athlete context are rather inconclusive concerning the adaptiveness of this goal type. On the one hand, performance approach goals have been found to be positively associated with increased athlete performance (Stoeber, Uphill, \& Hotham, 2009), as well as intrinsic motivation in sports students (Cury, Elliot, Sarrazin, Da Fonseca, \& Rufo, 2002). On the other hand, athletes who strongly endorse performance approach goals have also been found to experience a fear of failure (Conroy et al., 2003) as well as a lack of respect for social conventions, opponents, rules, and officials (Stornes \& Ommundsen, 2004). In some cases, researchers have not been able to find any significant associations of this goal type, for example with indices of well-being (Adie et al., 2008; Adie et al., 2010) or intrinsic motivation (Conroy, Kaye, \& Coatsworth, 2006). Performance avoidance goals, however, have consistently been found to be maladaptive for experiences and behaviors in sport. This has been shown in terms of positive links between performance avoidance goals and negative reactions to im- 
perfections (Stoeber et al., 2008), concentration disruption, and worry (Morris \& Kavussanu, 2009), as well as negative links with positive affect (Adie et al., 2010), intrinsic motivation (Conroy et al., 2006), and incremental beliefs about sport ability and perceptions of physical education competence (Cury et al., 2002).

Aside from the definitions presented above, other types of goals are theoretically distinguishable and discussed in the literature (e.g., task goals, appearance goals, see Hulleman, Schrager, Bodmann, \& Harackiewicz, 2010; Mascret etal., 2015; Wang, Liu, \& Chua, 2017). To be conceptually precise (both in writing and operationalisation), in the current study, we focus mastery goals solely on intrapersonal standards (e.g., striving to develop one's skills and to be better than in the past), and performance goals solely on normative standards (e.g., striving to be better than others) in line with the overview model of Daumiller, Dickhäuser, and Dresel (2019). Following this literature review, the aforementioned types of achievement goals can be expected to differentially matter for elite athletes' experiences and behaviors, in particular, their burnout levels, psychosomatic stress symptoms, and use of coping strategies, as we will describe in the following sections.

\section{Achievement Goals and Elite Athletes' Burnout Levels and Psychosomatic Stress Symptoms}

Based on Maslach, Jackson, and Leiter (1996) and Raedeke and Smith (2001), athlete burnout can be described as (1) physical and emotional exhaustion, (2) reduced sense of accomplishment, and (3) sport devaluation. Despite having comparable intensive training and competition regimes, not all athletes experience similar burnout levels (Cresswell \& Eklund, 2007; Feigley, 1984). To this end, studies have found motivational quality (such as achievement goals) to be an important factor for explaining these individual differences (e.g., Lemyre, Hall, \& Roberts, 2008; Mäkikangas \& Kinnunen, 2016). Specifically, the motivational systems spanned up by focusing on different achievement goals can be considered as resources or determinants of primary and secondary appraisals of stressors (Folkman, Lazarus, Dunkel-Schetter, DeLongis, \& Gruen, 1986; see Daumiller \& Dresel, 2020). As mastery approach goals are focused on competence development, athletes who strongly endorse such goals may view stressful and exhausting achievement situations as positive and controllable learning opportunities, leading to associations with decreased burnout levels, while the opposite can be expected for individuals who are worried about failure and perceive achievement situations as threatening (which is typically the case when pursuing strong avoidance goals). Further, those who pursue performance goals may be more likely to base their self-worth on demonstrating ability, resulting in perceiving sports competitions or challenges as threatening and eventuating in stress and burnout symptoms.

Studies that have explored athlete burnout levels with achievement goals indicate the power of this approach for explaining individual differences therein. High-level student athletes with strong mastery goals have been found to be less prone to burnout experiences than their more performance goal-oriented counterparts (Sorkkila, Aunola, Samela-Aro, Tolvanen, \& Ryba, 2018). Moreover, Ingrell, Johnson, and Ivarsson (2018) reported in their longitudinal study on student athletes at sport compulsory schools that mastery goal orientation was significantly and negatively associated with sport devaluation and reduced sense of accomplishment, while for performance goal orientation, significant associations were not found. Similar relationships were reported for Norwegian elite winter sport athletes (Lemyre et al., 2008).

A notable limitation of the aforementioned studies is that they did not distinguish between approach and avoidance goals, which might be the reason for some of the respective nil findings. This limitation was overcome in a study including 309 French handball players from elite training centers, where mastery approach goals were associated with reduced sport devaluation while mastery avoidance goals were linked to a reduced sense of accomplishment (Isoard-Gautheur etal., 2013). Regarding performance goals, performance approach goals were positively linked to emotional and physical exhaustion, while no significant relationships emerged for performance avoidance goals (Isoard-Gautheur et al., 2013). Altogether, these findings highlight the usefulness of achievement goals for explaining burnout levels in athletes and the importance of differentiating between approach and avoidance goals. At the same time, the sparse empirical findings imply a need for further research, especially as it is not clear to which extent the findings by Isoard-Gautheur et al. (2013) can be generalized to elite athletes.

\section{Psychosomatic Stress Symptoms}

Aside from burnout, the high levels of performance elite athletes are required to achieve can result in psychosomatic stress symptoms. Such symptoms present in a physical manner but stem from psychological factors, for example, high stress leading to abdominal 
pain, sleep loss, headaches, or weight loss. They are especially problematic for elite athletes as they heavily rely on their physical health and functioning for performance success. Empirical evidence also indicates that psychosomatic stress symptoms are prevalent and maladaptive for elite athletes. For example, in a review on stress and sleep in elite soccer athletes, Nédélec, Halson, Abaidia, Ahmaidi, and Dupont (2015) reported that different psychological, sociological, and physiological stressors can result in reduced sleep quality and quantity, ultimately leading to compromised psychological and physiological functioning (see also Asplund \& Chang, 2020). Moreover, when comparing the mental health of German elite student-athletes with regular students, more frequent stress and somatoform symptoms were found for the elite athletes (Brand et al., 2012).

Taken together, the aforementioned findings indicate that psychosomatic stress symptoms are prevalent and may hinder the performance and functioning of elite athletes. When considering the aims of the present study, it is important to note that although psychosomatic stress symptoms and burnout experiences may overlap to an extent and can both be considered adverse responses, they constitute distinctly separable constructs (see also Raedeke \& Smith, 2004). Specifically, burnout focusses on subjective perceptions of reactions to stress factors regarding the athlete context (e.g., an athlete no longer seeing value in their sport after prolonged stress), while psychosomatic stress symptoms represent direct and domain-unspecific symptoms of psychological and physical nature (e.g., an athlete having headaches and difficulties sleeping or eating as a result of stress). Throughout the literature, the distinction between stress (also psychosomatic stress) and burnout has been clearly indicated in terms of both constructs being distinct from one another and having different antecedents, correlates, and consequences (Bauer et al., 2006; Meeusen, Van Dam, Brown-Mahoney, Van Zundert, \& Knape, 2010; Pines \& Keinan, 2005). While studies have suggested that achievement goals are an important factor to be considered along with coping strategies and athlete well-being (Raedeke \& Smith, 2004), to the best of our knowledge, research has yet to comprehensively consider the role of achievement goals for psychosomatic stress symptoms in elite athletes. With that being said, some preliminary empirical evidence exists in support of this relationship. Throughout a concussion recovery process, athletes with mastery goal orientations experienced decreased psychological and physical symptoms compared to their performance goal-oriented counterparts
(O’Rourke, Smith, Punt, Coppel, \& Breiger, 2017). This supports the potential importance of considering achievement goals to better understand elite athletes' psychosomatic stress. Similar to burnout, we expect that as the different goals that athletes pursue guide their assessments of achievement events (including patterns of coping and emotion), they should also matter for their psychosomatic stress symptoms.

\section{Coping Strategies as a Mechanism Between Achievement Goals and Strain}

Concerning the link between achievement goals, burnout levels, and psychosomatic stress symptoms, the different methods that athletes use to handle stressors can be considered to be important (i.e., their use of coping strategies; Goodger, Gorley, Lavallee, \& Harwood, 2007; Lazarus, 2000; Nicholls \& Pollman, 2008; Williams, 2001). Coping strategies describe behaviors and relationships that help athletes to deal with "the problems, joys, disappointments, and stresses of life" (Williams, 2001, p. 774) and are thought to be influenced by the goals that individuals pursue in achievement contexts (Kristiansen, Roberts, \& Abrahamsen, 2008; Lazarus, 1991). As described by Ntoumanis et al. (1999) goals are relevant for different levels of adaptive coping as they "bring to a particular situation different beliefs, commitments, and perceptions of what is at stake" (p. 318).

Researchers have identified a wealth of coping strategies over the years. Among these, strategies such as positive thinking, active stress coping, and seeking social support are prominently discussed and have been categorized as adaptive ${ }^{1}$ with regard to different populations throughout the literature (e.g., Hampel \& Petermann, 2006; Holton, Barry, \& Chaney, 2016; Prati \& Pietrantoni, 2009). Specifically, positive thinking involves reappraising stressful situations in a positive light; active stress coping entails attempting to use one's own psychological or behavioral resources to actively deal with stress; and social support involves turning to friends, partners, or family members in times of stress to discuss the situation and ultimately feel cared for. The adaptivity of such coping strategies has also been found within empirical investigations in the athlete context (Crocker \& Graham, 1995; Gaudreau, Blondin, \& Lapierre, 2002; Kristiansen \& Roberts, 2009; Ntoumanis \& Biddle, 1998). Given their positive role for maintaining athlete health, as well as their importance for dealing with burnout and stress in general (e.g., Shin et al., 2014), we focused on these strategies 
in the present study as well. In particular, we were interested in gathering a better understanding of whether the use of adaptive coping as a general mechanism (comprised of the aforementioned three strategies) would support athletes with their burnout and psychosomatic stress (in line with prior research that has also combined individual coping strategies into adaptive coping on a general level, e.g., Jonason et al., 2020; Sun et al., 2019).

When adding athletes' achievement goals into the equation, studies have found that mastery goals are more strongly and positively related to the use of adaptive coping strategies than performance goals (e.g., Kristiansen etal., 2008; Ntoumanis etal., 1999; Pensgaard \& Roberts, 2003). While little is known regarding the approach and avoidance aspects of goals, these empirical findings, along with those previously mentioned, support elite athletes' use of adaptive coping strategies as a mediating variable between achievement goals and burnout levels and psychosomatic stress symptoms.

\section{Research Questions and Hypotheses}

The main research aim of the present study was to investigate the relationship between elite athletes' achievement goals and their burnout levels and psychosomatic stress symptoms, along with the role that the use of adaptive coping strategies has in these relationships. Based on the theorizing of the different types of goals and previous empirical findings, we hypothesized:

(H1) Mastery approach goals are positively associated with use of adaptive coping strategies, and negatively associated with burnout levels and psychosomatic stress symptoms.

(H2) Mastery avoidance goals are negatively associated with use of adaptive coping strategies, and positively associated with burnout levels and psychosomatic stress symptoms.

(H3) Performance approach goals are positively associated with use of adaptive coping strategies, and negatively associated with burnout levels and psychosomatic stress symptoms.

(H4) Performance avoidance goals are negatively associated with use of adaptive coping strategies, and positively associated with burnout levels and psychosomatic stress symptoms.

(H5) The use of adaptive coping strategies mediates the effects of achievement goals on burnout levels and psychosomatic stress symptoms.

\section{Method}

\section{Procedure}

Elite athletes (operationalized as being a member of the national or state squad in their sport) were asked to answer an online questionnaire assessing their achievement goals, adaptive coping strategies, burnout levels, and questions concerning their socio-demographic background. Before beginning the survey, participants read the goals of the study and data protection policies and provided informed consent. There was no reason to assume that the survey could inflict any psychological harm to the participants.

\section{Participants}

We recruited participants by asking athlete coordinators to share our survey invitation with athletes in the respective squad and sending personalized invitations to athletes for whom we had contact details. As a result, 165 German elite athletes participated in the survey. We decided prior to conducting the study that we would only include those participants who filled out more than $1 / 3$ of the survey. The final sample consisted of 125 athletes ( 97 male, 28 female) with an average age of $23.7(S D=4.0)$ years. On average throughout the year, they were training for 12.2 hours a week $(S D=8.5)$, and had 28.1 competitions $(S D=15.7)$. The sports in which the athletes were active in included football, badminton, handball, gymnastics, ice hockey, skiing, basketball, volleyball, swimming, boxing, squash, and tennis, among others.

\section{Measures}

We asked the participants to report their achievement goals, burnout levels, psychosomatic symptoms, and adaptive coping strategies with regard to the last six months in reference to the particular sport the participant was involved in.

Achievement goals. Achievement goals were measured using a version of the achievement goal scale by Daumiller et al. (2019) adapted for the athlete context. We measured mastery approach (e.g., "I want to develop my sporting skills as much as possible"; $\alpha=.91$ ), mastery avoidance (e.g., "I want to avoid not developing my competences further"; $\alpha=.70$ ), performance approach (e.g., "It is my goal to perform better than other athletes"; $\alpha=.88$ ), and performance avoidance (e.g., "I don't want to be worse than the other athletes"; $\alpha=.88$ ) goals with four items each. Answers 
Table 1

Descriptive Statistics and Bivariate Correlations for Achievement Goals, Coping Strategies, Burnout Levels, and Psychosomatic Stress Symptoms

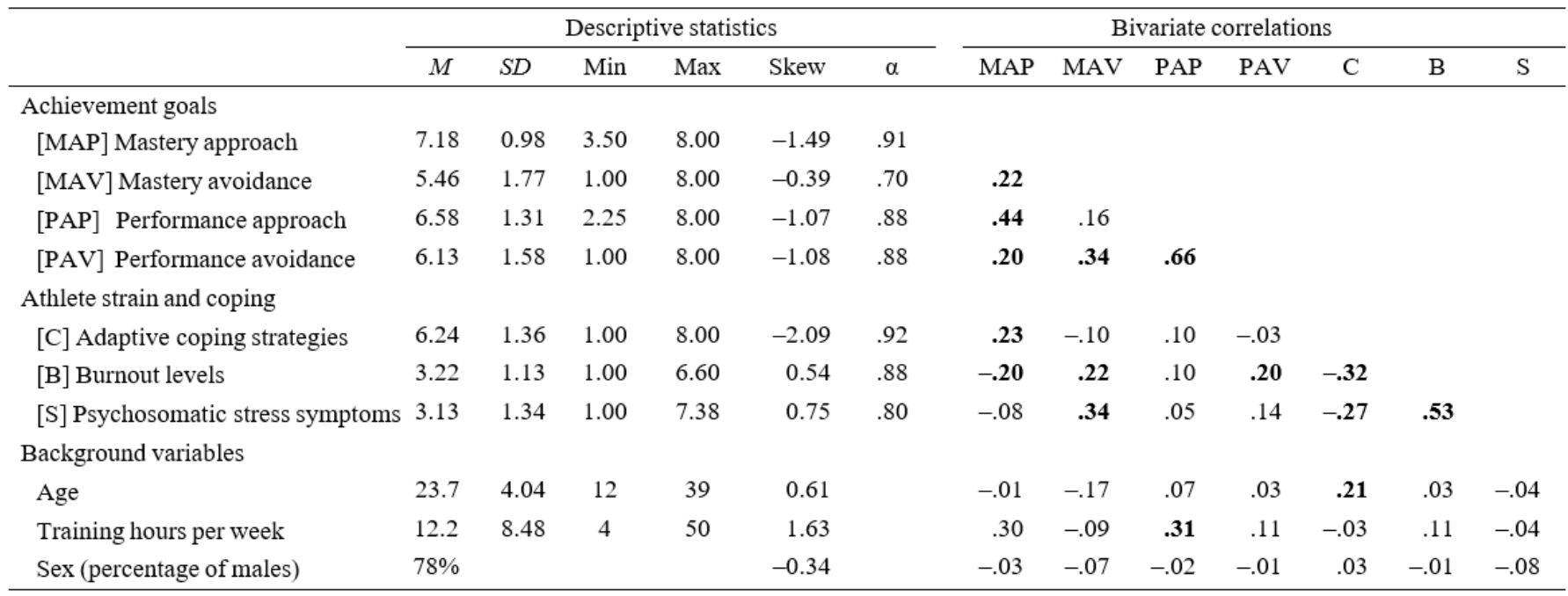

Note. $N=125$. All bolded correlations are statistically significant at $p<.05$.

were recorded on a Likert-type scale ranging from 1 ( $d o$ not agree at all) to 8 (agree completely).

Athlete burnout levels. We used the German version of the Athlete Burnout Questionnaire (ABQ-D) by Ziemainz et al. (2004) to measure participants' burnout levels in the context of their sport. The item stem read "How often do you feel this way?", followed by five items assessing emotional and physical exhaustion (e.g., "I feel excessively exhausted by my exercise"), five items assessing sport devaluation (e.g., "I am not as interested in my sport as I used to be"), and five items assessing reduced sense of accomplishment (e.g., "I achieve many desirable things in my sport", negatively coded item). Answers were recorded on a Likerttype scale ranging from 1 (almost never) to 8 (very often). As we were interested in burnout levels as a whole, we considered the construct on the overall scale level (see Brenninkmeijer \& van Yperen, 2003) by averaging the three sub-aspects to a uniform indicator of burnout level $(\alpha=.88)$.

Psychosomatic stress symptoms. To measure psychosomatic symptoms of stress, we used the respective subscale of the validated Stress and Coping Inventory (SCI) by Satow (2012). This inventory has been used in numerous studies to measure psychosomatic stress symptoms as well as the use of coping strategies (e.g., Steinert \& Haesner, 2019; Steiner-Hofbauer \& Holzinger, 2020). The item stem read "Stress and pressure can cause physical symptoms. Which of the following statements have you observed in the last six months?" followed by thirteen items listing psychosomatic symptoms (e.g., "I don't sleep well", "I often suffer from headaches"; $\alpha=.80)$ answered on a Likert-type scale ranging from 1 (do not agree) to 8 (agree completely).

Adaptive coping strategies. We again used a subscale of the Stress and Coping Inventory (SCI) by Satow (2012) to measure athletes' use of adaptive coping strategies. The item stem read "How do you deal with stress?" and included four items about positive thinking (e.g., "When confronted with stress and pressure, I concentrate on the bright side"), four items about active stress management (e.g., "I actively think about how I can avoid time pressures"), and four items about social support (e.g., "When I am under pressure, I have people to help me"). Answers were recorded on a Likert-type scale ranging from 1 (do not agree) to 8 (agree completely). As we were interested in participants' use of coping as a general mechanism, we considered the construct on the overall scale level $(\alpha=.92$; in line with prior literature, e.g., Jonason et al., 2020; Sun et al., 2019, and justified by large correlations between the three different strategies: $\rho=.70-.87$ ).

\section{Analyses}

Analyses were conducted with Mplus 8.1 (Muthén \& Muthén, 2017) using MLR as an estimator to control for the fact that not all variables were normally distributed. To test our hypotheses, we conducted path modelling. Indirect effects were tested using the "model indirect" command in Mplus, which uses the 


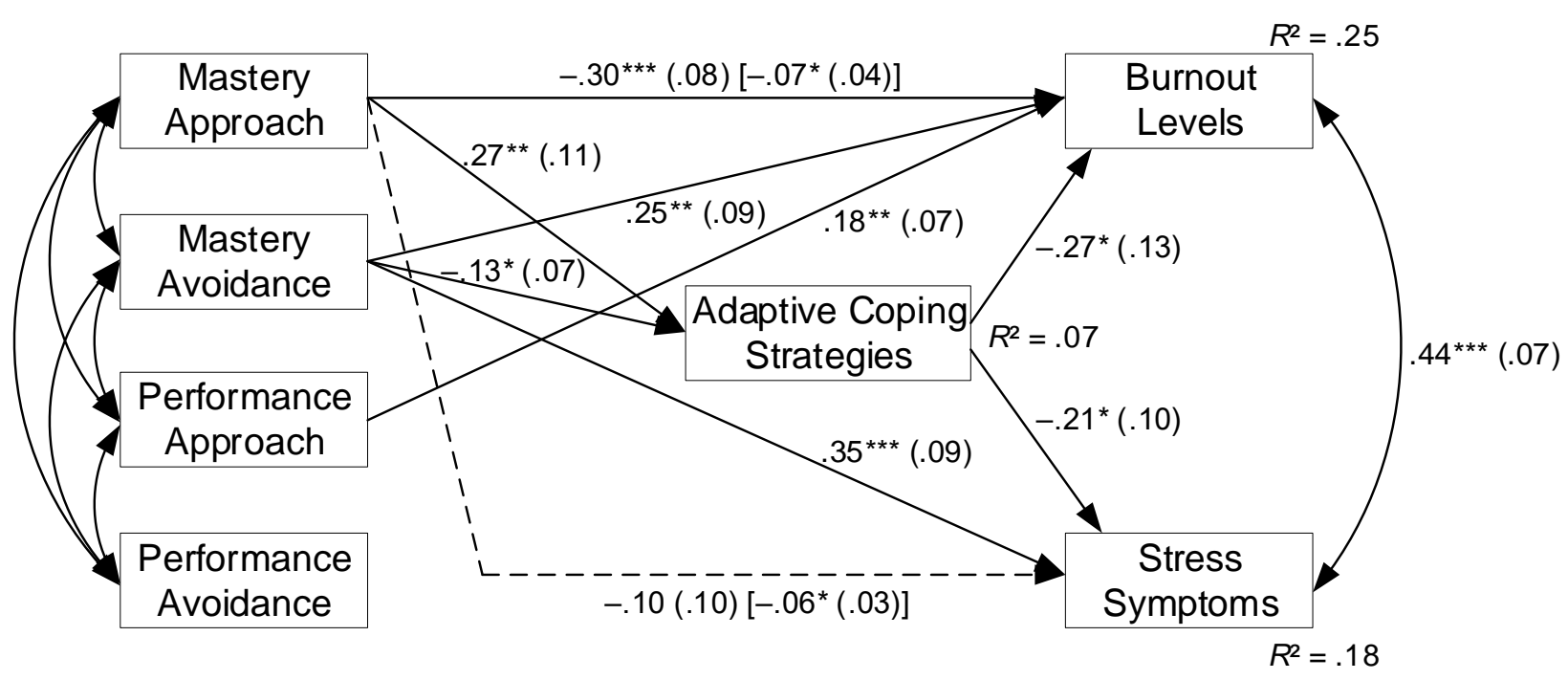

Figure 1. Path modelling and testing of the mediation effects between achievement goals, adaptive coping strategies, burnout levels, and psychosomatic stress symptoms. Presented are standardized regression coefficients with standard errors in round brackets. In square brackets, indirect effects are reported. Correlations between achievement goals were modelled but not presented for reasons of clarity. The model is fully saturated and perfectly fit the data with zero degrees of freedom. As such, this model does not provide a test of alternative models but allows for testing the statistical significance of all hypothesized paths in the model. Only statistically significant parameters at $\mathrm{p}<.05$ are displayed (all parameter estimators are presented in Table S1 in the Supplementary Materials).

delta method to calculate standard errors (MacKinnon, $2008)$. Missing values $(<10.4 \%$ for each item) were dealt with using the FIML estimator and the EM-algorithm for all analyses (Peugh \& Enders, 2004). Power analyses based on multiple regression analyses indicated that a sample size of 116 participants was required to detect medium effects (Faul, Erdfelder, Buchner, \& Lang, 2009). Monte Carlo power analyses revelated that this was also sufficiently large to detect small-to-medium indirect effects (Schoemann, Boulton, Short, 2017).

\section{Results}

\section{Preliminary Results}

Descriptive statistics for the achievement goals, the use of adaptive coping strategies, burnout levels, and psychosomatic stress symptoms are presented in Table 1. Elite athletes reported rather strong mastery approach and performance goals, while at the same time moderate levels of burnout levels and psychosomatic stress symptoms, and relatively high levels of adaptive coping strategies. Most importantly, there were strong interindividual differences between the athletes which were particularly strong for mastery avoidance goals.
Effects of Achievement Goals on Burnout Levels, Psychosomatic Stress Symptoms, and Use of Coping Strategies

Through path modelling, we investigated the direct effects of achievement goals on burnout levels, psychosomatic stress symptoms, and use of adaptive coping strategies, and examined how use of these coping strategies mediated the effects of achievement goals on burnout levels and psychosomatic stress symptoms (see Figure 1).

We found that mastery approach goals were negatively associated with burnout levels (but not psychosomatic stress symptoms; in terms of direct effects), and positively associated with use of coping strategies. Conversely, strong mastery avoidance goals were associated with increased burnout levels and increased psychosomatic stress symptoms as well as reduced use of coping strategies. Performance approach goals were positively associated with burnout levels, however neither with coping strategies nor with stress symptoms. Finally, we did not observe any statistically significant effects for performance avoidance goals. Regarding the mediation effects, we found statistically significant indirect effects from mastery approach goals on burnout levels and psychosomatic stress symptoms, mediated 
by use of coping strategies, however for the other types of goals, no significant mediating effects were found.

Altogether, we found that substantial amounts of variance in participants' psychosomatic stress symptoms $\left(R^{2}=.18\right)$ and burnout levels $\left(R^{2}=.25\right)$ were explained. Further, these two aspects were not very strongly correlated and were differentially associated with the achievement goals.

\section{Discussion}

The present study aimed to expand our knowledge about the relevance of achievement goals for how elite athletes experience and deal with sport stressors. We took a motivational perspective to explain why some elite athletes may handle these negative consequences more adaptively than others. While the achievement goal approach has already been successfully used to describe the motivations of this understudied population, previous research often did not fully consider the valence of the goals (i.e., their approach or avoidance components) - a limitation we addressed with the present work. Moreover, the present study advanced the current state of research by incorporating the use of adaptive coping strategies in explaining how goals matter for individuals dealing with sport stressors. Regarding the latter, we included two important aspectsburnout levels and psychosomatic stress symptoms. The substantial amount of explained variance of both aspects as well as their interrelations support the usefulness of investigating them simultaneously and the relevance of achievement goals for explaining differences within them.

Our hypotheses were partially supported in that achievement goals were found to differentially predict burnout levels, psychosomatic stress symptoms, and use of coping strategies in elite athletes (with mastery approach goals being especially adaptive and mastery avoidance goals being maladaptive). Moreover, as reported in previous literature on athletes, our study also indicated high mean levels of mastery approach and performance goals as well as high levels of coping strategies, and moderate levels of burnout levels and psychosomatic stress symptoms with substantial interindividual differences (Fernández-Rio, Cecchini Estrada \& Méndez-Giménez, 2017; Fernández-Rio et al., 2014; Lochbaum et al., 2017). This supports the relevance of achievement goals for understanding elite athletes' stress experiences and coping strategies, and suggests the importance of conducting further research focused on replicating and elaborating on these effects.
Mastery approach goals were positively related to adaptive coping strategies and negatively related to burnout levels (Hypothesis 1). Besides these direct effects, they were indirectly negatively related to psychosomatic stress symptoms. These results speak to the beneficial nature of mastery approach goals found in previous literature on athletes (e.g., Adie et al., 2008; Fernández-Rio et al., 2013). Specifically, athletes who strongly focus on developing their competencies and are interested in dealing with intrapersonal challenges might experience more conviction and coherence in their actions, and therefore be more resistant and resilient in terms of burnout levels and psychosomatic stress symptoms (Ingrell et al., 2018; Isoard-Gautheur et al., 2013; Lemyre et al., 2008; Vitali, Bortoli, Bertinato, Robazza, \& Schena, 2015).

Besides this, we found unfavorable associations for mastery avoidance goals regarding how elite athletes experienced and dealt with sport stressors (Hypothesis 2). These findings are particularly interesting, as there is an ongoing debate about the usefulness of mastery avoidance goals (see Ciani \& Sheldon, 2010; Murayama et al., 2012; Baranik et al., 2010). While it should first be mentioned that the reliability of the mastery avoidance goal subscale was lower than that of the other goals (albeit still satisfactory), our findings suggest that individuals within the elite athlete context differ substantially in their pursuit of such goals, which is in turn meaningfully associated with their use of coping strategies, burnout levels, and psychosomatic stress symptoms. Athletes who focus on avoiding losing skills they already have, as opposed to learning and fostering new skills, may struggle more in improving their personal and athletic skills. This might lead to a reduced sense of accomplishment in sports as well as an increase in sport devaluation, a problematic combination in terms of early drop out of high-performance sports (Isoard-Gautheur et al., 2013; Le Bars, Gernigon \& Ninot, 2009; Raedeke \& Smith, 2001).

Regarding Hypothesis 3, we found performance approach goals to be positively related to burnout levels, but did not identify any other significant relationships. Athletes who consistently try to outplay their rivals might struggle to appreciate their engagement in sports for the sake of having fun and performing well, and stress a focus on output and winning. As such, this motivational orientation might matter primarily for how individuals interpret their achievement situations and stressors therein. This may explain why we found statistically significant associations for burnout levels but not for psychosomatic stress symptoms. Furthermore, the fact that elite athletes striving to perform better than 
others reported higher burnout levels may point to negative effects of emphasizing competitive attitudes and performance climate in high performance sports training groups (Alvarez, Balaquer, Castillo \& Duda, 2012; Isoard-Gautheur et al., 2013; Rice et al., 2016).

We did not find significant associations between performance avoidance goals and use of adaptive coping strategies, psychosomatic stress, or burnout levels, contrary to Hypothesis 4 . This finding was surprising, as we expected higher burnout levels and more psychosomatic stress symptoms in athletes in fear of performing worse than others. Our findings imply that such reactions might be more strongly associated with mastery avoidance goals than with performance avoidance goals. This is also supported by the findings of IsoardGautheur et al. (2013), who did not identify significant associations for performance avoidance goals and found unfavorable associations for mastery avoidance goals. To elaborate, elite athletes can be expected to have achieved high levels of mastery within their sport and to identify with their sport on a personal and intimate level. Given these high standards, it may be the case that they are more affected by the prospect of losing their skills or not developing them further than they are by performing worse than others. In line with this, Allen and Hopkins (2018) describe in their systematic review that elite athletes have a fleeting period of peak competitive performance in their lifetime. Thus, elite athletes may be especially affected by concerns about having already peaked in their sport, and in turn, by worries about having a lack of improvement or regressing (see also Larson et al., 2019). To date, most research has not investigated achievement goals with burnout and stress in athletes by distinguishing between approach and avoidance goals, making this finding a valuable step towards gathering a comprehensive understanding of the role of achievement goals for athletes' cognitions and behaviors.

Finally, we found that the use of adaptive coping strategies mediated mastery approach goals and burnout levels/psychosomatic stress symptoms, while for the other goals, no significant mediating effects were found (partial support for Hypothesis 5). This implies that elite athletes with a high level of mastery goals often used these coping strategies to greater extent, which can help in reducing burnout levels and psychosomatic stress symptoms (Kristiansen et al., 2008; Ntoumanis et al., 1999; Pensgaard \& Roberts, 2003). One important finding here however, was that the use of coping strategies only partially mediated these relationships, with substantial direct effects between goals and burnout levels as well as psychosomatic stress symptoms remaining. This might imply that athletes likely also differ in their thought processes about successes and failures, and as a result of this mindset, differ in their stress experiences-beyond differences in their coping behaviors.

In sum, elite athletes with weak mastery approach goals and/or strong mastery avoidance goal pursuit can be regarded as a group that is more likely to suffer from suboptimal handling of stressors and more pronounced experiences of stress. This burden on burnout levels and psychosomatic stress symptoms is particularly the case if they employ minimal adaptive coping strategies. Such athletes can be expected to require support from coaches, especially in the field of mental training and coaching (Alvarez et al., 2012). As the coach-athlete relationship is a key factor for elite athletes who suffer from high burnout levels (McGee \& DeFreese, 2019), coaches should support athletes in pursuing adaptive goals (i.e., mastery approach as opposed to mastery avoidance goals) and using adaptive coping strategies. Specifically, not only individual, but organizational or combined efforts in the form of targeting psychosocial interventions that also consider motivational aspects can be considered effective in mitigating and preventing athletes from burning out and dropping out (Eklund \& DeFreese, 2015). Adding to this, intervention suggestions (DeFreese, Raedeke \& Smith, 2015) and programs have been developed to help young elite athletes deal with chronic stress when facing a combined school and sport career (Gledhill, Forsdyke, \& Murray, 2018; Sallen, Hemming \& Richartz, 2017). Moreover, the literature reflects an increasing focus on the beneficial effects of mindfulness training (Gustafsson, DeFreese \& Madigan, 2017; Li, Zhu, Zhang, Gustafsson, \& Chen, 2019; Moen, Federici, Abrahamsen, 2015; Moen, Abrahamsen \& Furrer, 2015). Lastly, athletes' perceptions of a mastery team climate predicting mastery approach goals (Morris \& Kavussanu, 2008) and sportsmanship behaviors (Laparidis, Papaioannou, Vretakou, \& Morou, 2003) again speak to the importance of combined-person efforts for supporting athletes. Thus, incorporating reflections on athletes' goal pursuit into the aforementioned strategies can be considered an auspicious avenue for better supporting this population.

\section{Limitations and Future Directions}

When interpreting the contributions of our study to the elite athlete literature concerning burnout levels, psychosomatic stress symptoms, and coping strategies, 
some limitations need to be borne in mind. First, we focused on coping strategies that have been perceived as adaptive within the literature. However, they may not be perceived this way for every individual in each situation, and thus, future research may profit from including a wider array of coping strategies as well as potential moderators that may cause certain coping strategies to be adaptive or maladaptive. Adding to this, it may be especially interesting to examine coping strategies deemed to be maladaptive within the literature and their associations with avoidance goals. Next, our study design was correlational and thus, causal explanations cannot be drawn. While it theoretically stands to reason that depending on the pursued achievement goals, individuals should differentially perceive and react to stressors, reciprocal effects from burnout and stress experiences on changes in motivations cannot be ruled out (see Martinent, Decret, Guillet-Descas, \& IsoardGautheur, 2014). In particular, it might be the case that burnout and stress experiences elicit concerns about maintaining one's competencies and as such, lead to the adoption of mastery avoidance goals to greater extent. Future research should investigate how these variables function over time using longitudinal designs, which would also allow for the testing of the proposed mediation effects beyond mere associations (see Maxwell \& Cole, 2007 for a review of cross-sectional mediation models). To better understand how athletes with different levels and combinations of achievement goals function over time in terms of their coping strategies, burnout levels, and psychosomatic stress symptoms, incorporating a goal profile approach may also be an especially interesting research avenue, as also suggested by Harwood and Chan (2010). Moreover, the measures used in the current study were self-reported. While this approach is very sensible to assess motivations and the subjective responses to stressors that we were interested in, future research would profit from supplementing the assessed symptoms with more objective indicators, particularly regarding clinically relevant symptoms or implicit measures (see Gerber, Brand, Antoniewicz, \& Isoard-Gautheur, 2019; Gerber, Gustafsson, Kellmann, \& Ludyga, 2018).

\section{References}

Adie, J. W., Duda, J. L., \& Ntoumanis, N. (2008). Achievement goals, competition appraisals, and the psychological and emotional welfare of sport participants. Journal of Sport and Exercise Psychology, 30, 302-322. https://doi.org/10.1123/jsep.30.3.302

Adie, J. W., Duda, J. L., \& Ntoumanis, N. (2010). Achievement goals, competition appraisals, and the well-and ill- being of elite youth soccer players over two competitive seasons. Journal of Sport and Exercise Psychology, 32, 555-579. https://doi.org/10/d4j9

Allen, S. V., \& Hopkins, W. G. (2015). Age of peak competitive performance of elite athletes. Sports Medicine, 45, 1431-1441. https://doi.org/10/f7x4rq

Alvarez, M. S., Balaguer, I., Castillo, I., \& Duda, J. L. (2012). The coach-created motivational climate, young athletes' well-being, and intentions to continue participation. Journal of Clinical Sport Psychology, 6, 166179. https://doi.org/10.1123/jcsp.6.2.166

Asplund C., Chang C.J. (2020) The role of sleep in psychological well-being in athletes. In E. Hong \& A. Rao (Eds.), Mental health in the athlete. Springer: Cham, Switzerland. https://doi.org/10.1007/978-3-03044754-0_23

Baranik, L., Stanley, L., Bynum, B., \& Lance, C. (2010). Examining the construct validity of mastery-avoidance achievement goals. Human Performance, 23, 265-282. https://doi.org/10/g86

Bauer, J., Stamm, A., Virnich, K., Wissing, K., Müller, U., Wirsching, M., \& Schaarschmidt, U. (2005). Correlation between burnout syndrome and psychological and psychosomatic symptoms among teachers. International Archives of Occupational and Environmental Health, 79, 199-204. http://doi.org/10.1007/s00420-005-0050-y

Brand, R., Wolff, W., \& Hoyer, J. (2012). Psychological symptoms and chronic mood in representative samples of elite student-athletes, deselected student-athletes and comparison students. School Mental Health, 5, 166174. https://doi.org/10/f5szbn

Brenninkmeijer, V., \& van Yperen, N. (2003). How to conduct research on burnout. Occupational and Environmental Medicine, 60, 16-20. https://doi.org/10.1136/oem.60.suppl_1.i16

Ciani, K. D., \& Sheldon, K. M. (2010). Evaluating the mastery-avoidance goal construct. Psychology of Sport and Exercise, 11, 127-132. https://doi.org/10.1016/j.psychsport.2009.04.005

Conroy, D. E., Elliot, A. J., \& Hofer, S. M. (2003). A 2x2 achievement goals questionnaire for sport. Journal of Sport \& Exercise Psychology, 25, 456-476. https://doi.org/10.1123/jsep.25.4.456

Conroy, D. E., Kaye, M. P., \& Coatsworth, J. D. (2006). Coaching climates and the destructive effects of mastery avoidance achievement goals on situational motivation. Journal of Sport and Exercise Psychology, 28, 69-92. https://doi.org/10.1123/jsep.28.1.69

Cresswell, S., \& Eklund, R. (2007). Athlete burnout. Sport Psychologist, 21, 1-20. https://doi.org/10/ggcrk4

Crocker, P., \& Graham, T. (1995). Coping by competitive athletes with performance stress. The Sport Psychologist, 9, 325-338. https://doi.org/10.1123/tsp.9.3.325

Cury, F., Elliot, A. J., Sarrazin, P., Da Fonseca, D., \& Rufo, M. (2002). The trichotomous achievement goal model and intrinsic motivation. Journal of Experimental 
Social Psychology, 38, 473-481. https://doi.org/10.1016/S0022-1031(02)00017-3

Daumiller, M., Dickhäuser, O., \& Dresel, M. (2019). University instructors' achievement goals for teaching. Journal of Educational Psychology, 111, 131-148. https://doi.org/10.1037/edu0000271

Daumiller M., \& Dresel M. (2020). Researchers' achievement goals, work stress, and professional development. Contemporary Educational Psychology, 61, 101843. https://doi.org/10.1016/j.cedpsych.2020.101843

Daumiller, M., Rinas, R., \& Jaitner, D. (2021). The relevance of stability and change of achieve-ment goals for self-regulated motor learning processes and outcomes. Sport, Exercise, and Performance Psychology. Advanced online publication. https://doi.org/10.1037/spy0000260

DeFreese, J., Raedeke, T., \& Smith, A. (2015). Individual and organizational solutions to athlete burnout. In J. Williams \& V. Krane (Eds.), Applied sport psychology (pp. 444-461). New York, NY: McGraw-Hill.

Eklund, R. \& DeFreese. J. (2015). Athlete burnout. International Journal of Applied Sports Sciences, 27, 63-75. https://doi.org/10.24985/ijass.2015.27.2.63

Elliot, A. J., \& McGregor, H. A. (2001). A 2x2 achievement goal framework. Journal of Personality and Social Psychology, 80, 501-519. https://doi.org/10.1037/00223514.80.3.501

Faul, F., Erdfelder, E., Buchner, A., \& Lang, A.-G. (2009). Statistical power analyses using G*Power 3.1. Behavior Research Methods, 41, 1149-1160. https://doi.org/10.3758/BRM.41.4.1149

Feigley, D. (1984). Psychological burnout in high-level athletes. The Physician and Sportsmedicine, 12, 108-119. https://doi.org/10.1080/00913847.1984.11701971

Fernández-Rio, J., Cecchini Estrada, J. A., \& MéndezGiménez, A. (2017). Does context, practice or competition affect female athletes' achievement goal dominance, goal pursuit, burnout and motivation? Journal of Human Kinetics, 59, 91-105. https://doi.org/10.1515/hukin-2017-0150

Fernández-Rio, J., Cecchini Estrada, J. A., MendezGimenez, A., Fernández-Garcia, B., \& Saavedra, P. (2014). $2 \times 2$ dominant achievement goal profiles in high-level swimmers. European Journal of Sport Science, 14, 265-272. https://doi.org/10/d4kc

Folkman, S., Lazarus, R. S., Dunkel-Schetter, C., DeLongis, A., \& Gruen, R. J. (1986). Dynamics of a stressful encounter. Journal of Personality and Social Psychology, 50, 992-1003. https://doi.org/10.1037/00223514.50.5.992

Folkman, S., \& Moskowitz, J. T. (2004). Coping: Pitfalls and promise. Annual Review of Psychology, 55, 745774. https://doi.org/10.1146/annurev.psych.55.090902.141456

Gaudreau, P., Blondin, J., \& Lapierre, A. (2002). Athletes' coping during a competition. Psychology of Sport and Exercise, 3, 125-150. https://doi.org/10/frjvdx
Gerber, M., Brand, R., Antoniewicz, F., \& Isoard-Gautheur, S. (2019). Implicit and explicit attitudes towards sport among young elite athletes with high versus low burnout symptoms. Journal of Sports Sciences, 37, 1-8. https://doi.org/10/d4kd

Gerber, M., Gustafsson, H., Kellmann, M., \& Ludyga, S. (2018). Usefulness of the ABQ as a screening tool for the detection of clinically relevant burnout symptoms among young elite athletes. Psychology of Sport and Exercise, 39, 104-113. https://doi.org/10/gd8pxw

Gledhill, A., Forsdyke, D., \& Murray, E. (2018). Psychological interventions used to reduce sports injuries. British Journal of Sports Medicine, 52, 967-971. https://doi.org/10/gc2tn6

Goodger, K., Gorely, T., Lavallee, D., \& Harwood, C. (2007). Burnout in sport: A systematic review. The Sport Psychologist, 21, 127-151. https://doi.org/10.1123/tsp.21.2.127

Gustafsson, H., DeFreese, J., \& Madigan, D. J. (2017). Athlete burnout. Current Opinion in Psychology, 16, 109113. https://doi.org/10.1016/j.copsyc.2017.05.002

Hampel, P., \& Petermann, F. (2006). Perceived stress, coping, and adjustment in adolescents. Journal of Adolescent Health, 38, 409-415. https://doi.org/10.1016/j.jadohealth.2005.02.01

Harwood, C. G., \& Chan, D. K. (2010). Achievement goals and coping in sport. In A. R. Nicholls (Ed.), Coping in sport (pp. 195-215). New York, NY: Nova Science.

Harwood, C., Spray, C., \& Keegan, R. (2008). Achievement goal theories in sport. In R. Horn, \& S. Thelma (Eds.), Advances in sport psychology (pp. 157-185). Champaign, IL: Human Kinetics.

Holton, M. K., Barry, A. E., \& Chaney, J. D. (2016). Employee stress management. Work, 53, 299-305. https://doi.org/10.3233/WOR-152145

Hulleman, C., Schrager, S., Bodmann, S., and Harackiewicz, J. (2010). A meta-analytic review of achievement goal measures. Psychological Bulletin, 136, 422449.https://doi.org/10/dkdjkcIngrell, J., Johnson, U., \& Ivarsson, A. (2018). Developmental changes in burnout perceptions among student-athletes. International Journal of Sport and Exercise Psychology, 17, 509-520. https://doi.org/10.1080/1612197x.2017.1421679

Isoard-Gautheur, S., Guillet-Descas, E., \& Duda, J. L. (2013). How to achieve in elite training centers without burning out. Psychology of Sport and Exercise, 14, 7283. https://doi.org/10/f4h2z4

Jaitner, D., Rinas, R., Becker, C., Niermann, C., Breithecker, J. \& Mess, F. (2019). A systematic review of achievement goal motivation in school physical education. Frontiers in Education, 4. https://doi.org/10.3389/feduc.2019.00070

Jonason, P. K., Talbot, D., Cunningham, M. L., \& Chonody, J. (2020). Higher-order coping strategies. Personality and Individual Differences, 155. https://doi.org/10.1016/j.paid.2019.109755 
Kaplan, A., \& Maehr, M. L. (1999). Achievement goals and student well-being. Contemporary Educational Psychology, 24, 330-358. https://doi.org/10.1006/ceps.1999.0993

Kavussanu, M. (2006). Motivational predictors of prosocial and antisocial behaviour in football. Journal of Sports Sciences, 24, 575-588. https://doi.org/10.1080/02640410500190825

Kavussanu, M., White, S. A., Jowett, S., \& England, S. (2011). Elite and non-elite male footballers differ in goal orientation and perceptions of parental climate. International Journal of Sport and Exercise Psychology, 9, 284-290. https://doi.org/10/ccbzn8

Kristiansen, E., \& Roberts, G. C. (2010). Young elite athletes and social support. Scandinavian Journal of Medicine \& Science in Sports, 20, 686-695. https://doi.org/10/bm5qjr

Kristiansen, E., Roberts, G. C., \& Abrahamsen, F. E. (2008). Achievement involvement and stress coping in elite wrestling. Scandinavian Journal of Medicine \& Science in Sports, 18, 526-538. https://doi.org/10.1111/j.16000838.2007.00646.x

Laparidis, K., Papaioannou, A., Vretakou, V., \& Morou, A. (2003). Motivational climate, beliefs about the bases of success, and sportsmanship behaviors of professional basketball athletes. Perceptual and Motor Skills, 96, 1141-1151. https://doi.org/10/c6bjxs

Larson, H. K., McHugh, T.-L. F., Young, B. W., \& Rodgers, W. M. (2019). Pathways from youth to masters swimming: Exploring long-term influences of youth swimming experiences. Psychology of Sport and Exercise, 41, 12-20. https://doi.org/10/d4kf

Lazarus, R. S. (2000). Toward better research on stress and coping. American Psychologist, 55, 665-673. https://doi.org/10.1037/0003-066x.55.6.665

Le Bars, H., Gernigon, C., \& Ninot, G. (2009). Personal and contextual determinants of elite young athletes' persistence or dropping out over time. Scandinavian Journal of Medicine \& Science in Sports, 19, 274-285. https://doi.org/10/b3ch4g

Lemyre, P. N., Hall, H., \& Roberts, G. (2008). A social cognitive approach to burnout in elite athletes. Scandinavian Journal of Medicine \& Science in Sports, 18, 221234. https://doi.org/10/bvmc95

Li, C., Zhu, Y., Zhang, M., Gustafsson, H., \& Chen, T. (2019). Mindfulness and athlete burnout. International Journal of Environmental Research and Public Health, 16, 1-13. https://doi.org/10.3390/ijerph16030449

Mäkikangas, A., \& Kinnunen, U. (2016). The person-oriented approach to burnout: A systematic review. Burnout Research, 3, 11-23. https://doi.org/10.1016/j.burn.2015.12.002

Martinent, G., Decret, J.-C., Guillet-Descas, E., \& IsoardGautheur, S. (2014). A reciprocal effects model of the temporal ordering of motivation and burnout among youth table tennis players in intensive training settings.
Journal of Sports Sciences, 32, 1648-1658. https://doi.org/10/dhq8

Maslach, C., Jackson, S. E., Leiter, M. P., Schaufeli, W. B., \& Schwab, R. L. (1986). Maslach burnout inventory. Palo Alto, CA: Consulting Psychologists.

Mascret, N., Elliot, A. J., \& Cury, F. (2015). Extending the $3 \times 2$ achievement goal model to the sport domain. Psychology of Sport and Exercise, 17, 7-14. https://doi.org/10/f62px6

Maxwell, S. E., \& Cole, D. A. (2007). Bias in cross-sectional analyses of longitudinal mediation. Psychological Methods, 12, 23-44. https://doi.org/10.1037/1082989x.12.1.23

McGee, V., \& DeFreese, J. D. (2019). The coach-athlete relationship and athlete psychological outcomes. Journal of Clinical Sport Psychology, 13, 152-174. https://doi.org/10/dhq5

MacKinnon, D. (2008). Introduction to statistical mediation analysis. New York, NY: Taylor and Francis.

Meeusen, V., Van Dam, K., Brown-Mahoney, C., Van Zundert, A., \& Knape, H. (2010). Burnout, psychosomatic symptoms and job satisfaction among Dutch nurse anaesthetists. Acta Anaesthesiologica Scandinavica, 54, 616-621. https://doi.org/10/fs9sfj

Moen, F., Federici, R. A., \& Abrahamsen, F. (2015). Examining possible relationships between mindfulness, stress, school-and sport performances and athlete burnout. International Journal of Coaching Science, 9(1), 3-19.

Moen, F., Furrer, P., \& Abrahamsen, F. (2015). The effects from mindfulness training on Norwegian junior elite athletes in sport. International Journal of Applied Sports Sciences, 27, 98-113. https://doi.org/10.24985/ijass.2015.27.2.98

Morris, R. L., \& Kavussanu, M. (2008). Antecedents of approach-avoidance goals in sport. Journal of Sports Sciences, 26, 465-476. https://doi.org/10.1080/02640410701579388

Morris, R. L., \& Kavussanu, M. (2009). The role of approach-avoidance versus task and ego goals in enjoyment and cognitive anxiety in youth sport. International Journal of Sport and Exercise Psychology, 7, 185-202. https://doi.org/10.1080/1612197x.2009.9671899

Murayama, K., Elliot, A. J., \& Friedman, R. (2012). Achievement goals. In R. Ryan (Ed.), The oxford handbook of human motivation (pp. 191-207). New York, NY: Oxford University.

Muthén, L., \& Muthén, B. (2017). Mplus (version 8.1) [Computer Software]. Los Angeles, CA: Muthén \& Muthén.

Nédélec, M., Halson, S., Abaidia, A., Ahmaidi, S., \& Dupont, G. (2015). Stress, sleep and recovery in elite soccer. Sports Medicine, 45, 1387-1400. https://doi.org/10/gdgzh2

Nicholls, A. R., \& Polman, R. C. J. (2008). Think aloud. Anxiety, Stress, \& Coping, 21, 283-294. https://doi.org/10/cn7p9t 
Ntoumanis, N., \& Biddle, S. (1998). The relationship between competitive anxiety, achievement goals, and motivational climates. Research Quarterly for Exercise and Sport, 69, 176-187. https://doi.org/10.1080/02701367.1998.10607682

Ntoumanis, N., Biddle, S. J. H., \& Haddock, G. (1999). The mediating role of coping mechanisms on the relationship between achievement motivation and affect in sport. Anxiety, Stress \& Coping, 12, 299-327. https://doi.org/10.1080/10615809908250480

O'Rourke, D. J., Smith, R. E., Punt, S., Coppel, D. B., \& Breiger, D. (2017). Psychosocial correlates of young athletes' self-reported concussion symptoms during the course of recovery. Sport, Exercise, and Performance Psychology, 6, 262-276. https://doi.org/10/gbthfg

Pensgaard, A. M., \& Roberts, G. C. (2003). Achievement goal orientations and the use of coping strategies among Winter Olympians. Psychology of Sport and Exercise, 4, 101-116. https://doi.org/10.1016/S14690292(01)00031-0

Peugh, J. L., \& Enders, C. K. (2004). Missing data in educational research. Review of Educational Research, 74, 525-556. https://doi.org/10.3102/00346543074004525

Pines, A. M., \& Keinan, G. (2005). Stress and burnout: The significant difference. Personality and Individual Differences, 39, 625-635. https://doi.org/10.1016/j.paid.2005.02.009

Pintrich, P. R. (2000). Multiple goals, multiple pathways. Journal of Educational Psychology, 92, 544-555. https://doi.org/10.1037/0022-0663.92.3.544

Prati, G., \& Pietrantoni, L. (2009). Optimism, social support, and coping strategies as factors contributing to posttraumatic growth. Journal of Loss \& Trauma, 14, 364-388. https://doi.org/10.1080/15325020902724271

Raedeke, T. D., \& Smith, A. L. (2004). Coping resources and athlete burnout. Journal of Sport and Exercise Psychology, 26, 525-541. https://doi.org/10.1123/jsep.26.4.525

Raedeke, T. D., \& Smith, A. L. (2001). Development and preliminary validation of an athlete burnout measure. Journal of Sport and Exercise Psychology, 23(4), 281306.

Rice, S., Purcell, R., De Silva, S., Mawren, D., McGorry, P., \& Parker, A. G. (2016). The mental health of elite athletes. Sports Medicine, 46, 1333-1353. https://doi.org/ 10/f9bvq9

Ryan, R. M., \& Deci, E. L. (2000). Intrinsic and extrinsic motivations. Contemporary Educational Psychology, 25, 54-67. https://doi.org/10.1006/ceps.1999.1020

Sallen, J., Hemming, K., \& Richartz, A. (2017). Facilitating dual careers by improving resistance to chronic stress. European Journal of Sport Science, 18, 112-122. https://doi.org/10/dhq6

Satow, L. (2012). Stress-und Coping-Inventar (SCI)[Stress and coping inventory] [PSYNDEX Tests-Nr. 9006508]. Elektronisches Testarchiv. Trier, Germany: ZPID.
Schoemann, A. M., Boulton, A. J., \& Short, S. D. (2017). Determining power and sample size for simple and complex mediation models. Social Psychological and Personality Science, 8(4), 379-386. https://doi.org/10.1177/1948550617715068

Shin, H., Park, Y. M., Ying, J. Y., Kim, B., Noh, H., \& Lee, S. M. (2014). Relationships between coping strategies and burnout symptoms. Professional Psychology: Research and Practice, 45, 44-56. https://doi.org/10.1037/a0035220

Sorkkila, M., Aunola, K., Salmela-Aro, K., Tolvanen, A., \& Ryba, T. V. (2018). The co-developmental dynamic of sport and school burnout among student-athletes. Scandinavian Journal of Medicine \& Science in Sports, 28, 1731-1742. https://doi.org/10/dhq7

Steinert, A., \& Haesner, M. (2018). Stress in retired adults stressors, symptoms and coping strategies. Ageing International, 44, 129-140. https://doi.org/10.1007/s12126018-9327-9

Steiner-Hofbauer, V., \& Holzinger, A. (2020). How to cope with the challenges of medical education. Academic Psychiatry. https://doi.org/10.1007/s40596-020-01193-1

Stoeber, J., Stoll, O., Pescheck, E., \& Otto, K. (2008). Perfectionism and achievement goals in athletes. Psychology of Sport and Exercise, 9, 102-121. https://doi.org/10/btfnch

Stoeber, J., Uphill, M. A., \& Hotham, S. (2009). Predicting race performance in triathlon. Journal of Sport and Exercise Psychology, 31, 211-245. https://doi.org/10.1123/jsep.31.2.211

Stornes, T., \& Ommundsen, Y. (2004). Achievement goals, motivational climate and sportspersonship. Scandinavian Journal of Educational Research, 48, 205-221. https://doi.org/10.1080/0031383042000198512

Sun, R., Vuillier, L., Hui, B. P. H., \& Kogan, A. (2019). Caring helps. PloS One, 14, e0213142. doi:10.1371/journal.pone.0213142

Tuominen-Soini, H., Salmela-Aro, K., \& Niemivirta, M. (2008). Achievement goal orientations and subjective well-being. Learning and Instruction, 18, 251-266. https://doi.org/10/dhtnq4

Van Yperen, N. W., Blaga, M., \& Postmes, T. (2014). A meta-analysis of self-reported achievement goals and nonself-report performance across three achievement domains (work, sports, and education). PLOS ONE, 9. https://doi.org/10/f5382v

Vitali, F., Bortoli, L., Bertinato, L., Robazza, C., \& Schena, F. (2015). Motivational climate, resilience, and burnout in youth sport. Sport Sciences for Health, 11, 103-108. https://doi.org/10.1007/s11332-014-0214-9

Wang, C. K. J., Biddle, S. J. H., \& Elliot, A. J. (2007). The $2 \times 2$ achievement goal framework in a physical education context. Psychology of Sport and Exercise, 8, 147168. https://dx.doi.org/10.1016/j.psychsport.2005.08.012

Wang, C. K. J., Liu, W. C., Sun, Y., \& Chua, L. L. (2017). Psychometric properties of the $3 \times 2$ achievement goal 
questionnaire for sport. International Journal of Sport and Exercise Psychology, 15, 460-474. https://dx.doi.org/10.1080/1612197X.2016.1142458

Williams, J. M. (2001). Psychology of injury risk and prevention. In R. N. Singer, H. A. Hausenblas, \& C. M. Janelle (Eds.), Handbook of sport psychology (2nd ed., pp. 766-786). New York, NY: John Wiley \& Sons.
Ziemainz, H., Abu-Omar, K., Raedeke, T., \& Krause, K. (2004). Burnout im Sport [Burnout in sport]. Leistungssport, 2004(6), 12-18.

Note. This is a pre-copyedited, author-produced PDF of an article submitted for publication. This paper is not the copy of record and may not exactly replicate the final, authoritative version of the article. The final article will be available, upon publication, via its DOI.

\section{Footnotes}

${ }^{1}$ When discussing coping strategies in the present study, we refer to strategies that have been empirically supported as adaptive within the athlete context. However, particularly for idiographic research (opposed to the nomothetic approach of the present work), it is important to acknowledge that what is adaptive for one person in a particular context may not be adaptive for another. Thus, despite our focus on adaptive strategies, individual and contextual differences are important to consider (see Folkman \& Moskowitz, 2004; Pensgaard \& Roberts, 2003). 